\title{
Effects of blended versus offline case-centered learning on academic performance and the development of critical thinking among undergraduate nursing students
}

\author{
Zhenzhen Yu \\ Fujian Medical University https://orcid.org/0000-0001-6989-8574 \\ Ling Shen \\ Fujian Medical University \\ Jiayuan Zhuang \\ Fujian Medical University \\ Yimin Chen \\ Fujian Medical University \\ Meijing Chen \\ Fujian Medical University \\ Yazhu Lin \\ Fujian Medical University \\ Rong Hu ( $\nabla$ ronghu1246@fjmu.edu.cn ) \\ https://orcid.org/0000-0002-3039-0498
}

\section{Research article}

Keywords: education, nursing, teaching methods, critical thinking

Posted Date: September 16th, 2019

DOI: https://doi.org/10.21203/rs.2.14460/v1

License: (9) (i) This work is licensed under a Creative Commons Attribution 4.0 International License. Read Full License 


\section{Abstract}

Background Educational reform, especially methods of teaching, has been a focus among nursing educators. This study explored the impact of blended versus offline case-centered learning on academic performance and the development of critical thinking among undergraduate nursing students. Methods A total of 269 undergraduate nursing students in two classes were taught Medical Nursing for 1 year. The two classes were randomly allocated to the experimental group (151 students), which undertook blended learning, or the control group (118 students), which undertook offline learning. The primary outcomes were academic performance and critical thinking ability. The Critical Thinking Disposition InventoryChinese Version (CTDI-CV) was used.Results At baseline, the students in the control group exhibited superior performance to that observed in the experimental group regarding all seven Professional Basic courses. There was no significant difference in academic performance in the Medical Nursing course after applying the two teaching methods; however, the median score was slightly higher in the experimental group than in the control group. In addition, there was no significant difference in the development of critical thinking ability between the blended and offline learning groups. In the experimental group, there was significant improvement compared with baseline in one of the seven CTDI-CV dimensions: critical thinking self-confidence $(p<0.05)$. In the control group, there was significant improvement compared with baseline in the total score $(p<0.05)$ and two of the seven dimensions: truth-seeking $(p=0.001)$ and systematicity $(p=0.010)$.Conclusions Our study confirms the effectiveness of blended and offline learning (both based on case-centered learning) for academic performance and components of critical thinking among undergraduate nursing students. Blended and offline case-centered learning should be applied to other nursing subjects in future studies. Moreover, further efforts to improve teaching are warranted.

\section{Background}

With the development of the social economy and the transition to the modern medical model and concept of health, developing comprehensive high-quality skills among nursing personnel is increasingly important. However, nowadays, much of nursing pedagogy relies on a traditional didactic approach that focuses on passive lecture-based delivery of content, leaving the students as passive participants who largely only take notes. Using this method, students do not have the opportunity to engage in contemplation, which is necessary during the learning process. Calls to change traditional educational strategies in order to provide effective and efficient education for nursing students are of increasing importance.

The goals of university nursing education are to teach theoretical knowledge, as well as develop the ability of students to critically analyze evidence [1]. Critical thinking is an important component of nursing education and integral to the discipline of nursing [2, 3]. It is currently an essential professional development core skill in nursing education and practice [4]. Worldwide, there is a need for nursing education to assist students in developing critical thinking, clinical reasoning, and clinical judgment skills [5]. Educational reform, especially regarding methods of teaching, has been a focus among nursing educators.

Active learning strategies applied to nursing education can enhance student understanding, stimulate inquiry, and encourage critical thinking [6]. To best engage students and promote learning, there has been a shift toward student-centered learning and engagement of students as active learners. Case-based learning (CBL) is an instructional method within the context of student-centered learning for facilitating learning through the use of case studies [7]. It is a long-established pedagogical method that is defined in a number of ways depending on the discipline and type of "case" employed [8]. McLean's definition of CBL is "an inquiry structured learning utilizing live or simulated patient cases to solve, or examine a clinical problem, with the guidance of a teacher and stated learning objectives" [9]. In nursing education, CBL can be applied to prepare students for clinical practice through the use of authentic clinical cases $[10,11]$ and increase their capacity to ask questions, reflect, and deal with problems $[12,13]$.

Previous research has indicated that $\mathrm{CBL}$ is a more effective technique than traditional didactic lectures for improving communication skills, problem-solving ability, and motivation in undergraduate nursing students $[14,15]$. In addition, the advantages of using CBL include increased focus on learning objectives, flexibility in the use of the cases, opportunity for the 
teacher to have more input toward the direction of learning, and enabling deeper learning. Owing to these benefits, $C B L$ is likely to become part of numerous curricula for medical and health professional courses [9].

Nowadays, technological advancements are rapidly changing nursing education in higher education settings. This has led to a push toward flexible delivery, online delivery, and blended learning. Blended learning refers to an educational approach that combines traditional classroom face-to-face methods with online materials and activities [16]. Garrison and Kanuka, early promoters of the blended learning approach, have highlighted several advantages of blended learning [17]. They describe blended learning as having the potential to transform the educational landscape by giving students more responsibility, control, and independence, while also increasing their capacities for critical and reflective thinking.

The concept of blended learning is considered crucial for the education of today's health students [18]. In recent years, blended learning has been used in nursing and medicine, and many studies have been conducted in this area [19-23]. However, the implementation of blended learning in nursing education remains controversial. Some investigations have shown that blended learning is favored by undergraduate nursing students, facilitates communication and active learning, and enhances self-efficacy regarding communication skills [24-26]. On the other hand, some researchers did not find a direct impact on knowledge acquisition or self-learning readiness [22]. Another study did not show differences regarding overall satisfaction with the teaching received [19]. Hence, there is concern regarding the outcomes associated with this method.

Although blended learning has been extensively used, there is limited knowledge regarding the effective application of blended learning in nursing curricula to support critical thinking. Therefore, the main objective of this study was to compare blended and offline learning (both based on case-centered learning) in terms of their impact on academic performance and the development of critical thinking among undergraduate nursing students.

\section{Methods}

\section{Study setting and population}

The second-year undergraduate nursing students at the Nursing School of Fujian Medical University (Fuzhou, China) formed the study population. The students were randomly assigned by a computer into two classes (classes 1 and 2) upon entry to the university, with 164 and 131 students in class 1 and class 2, respectively. Thus, randomization in this study occurred at the class level. An administrator employed by the university, who had no information regarding the recruitment or data collection, was invited to conduct the random allocation. Two labels (numbered 1 and 2) were placed in opaque envelopes, and the administrator subsequently requested the Medical Nursing teacher to draw one envelope at random. If "number 1" was picked, class 1 was to be the experimental group; otherwise, class 2 was to be the experimental group. As "number 1" was selected, there were 164 students in the experimental group and 131 in the control group at the beginning of the study. The experimental group involved eight subgroups, while the control group involved seven subgroups, with each subgroup consisting of approximately 20 students.

The general characteristics were compared between the two classes and there were no significant differences (Table 1). However, there were significant differences between the control and experimental groups in academic performance regarding all seven Professional Basic courses of the previous academic year $(p<0.05)($ Table 2$)$.

\section{Teaching approaches}

The Medical Nursing course was conducted over 1 academic year (two semesters), with 144 teaching hours in both the experimental and control groups. The same teacher, textbook, and additional resources were provided to both groups. An additional file shows the teaching arrangement in both groups in more detail [Additional file 1: Table S1]. The experimental group underwent blended learning, whereas the control group underwent offline case-centered learning. Although blinding of the students and teachers was not possible, the data analyst was blinded.

\section{Experimental group}

Page $3 / 13$ 


\section{Teaching arrangement}

The teaching arrangement in the experimental group is presented in Supplementary Table 2. The experimental group received blended learning, which combined online learning with offline flipped classrooms. The teacher prepared the content prior to each offline flipped classroom (Figure 1).

Figure 1 Tasks of the teacher prior to each offline flipped classroom

\section{Offline flipped classrooms}

All students had access to the chaoxing platform (http://i.mooc.chaoxing.com/space/index.shtml), where they watched the pre-recorded lecture videos and accessed the online quizzes, forums, and study materials. Students were required to watch the lecture videos, and subsequently divided into groups (approximately five students per group) to discuss the case and the question that the teacher provided prior to the class. In addition, they recorded their discussion, produced a report, and handed in the recording and report after the discussion. Questions could be asked in the online forums during the learning process (Figure 2).

Each offline flipped classroom involved approximately 20 students, and they were divided into four groups (approximately five students per group) based on the pre-class group discussions. To assess the students' mastery of the lesson prior to class, online quizzes, which lasted approximately $10 \mathrm{~min}$, were performed at the beginning of the flipped classroom. Subsequently, the teacher provided detailed explanations of the quiz questions according to the results, and the students reported what they had discussed prior to class. After each group completed the reporting, other groups asked questions or provided supplementary answers. The teacher commented on each report and summarized the results of the group discussions. Additionally, the teacher pointed out the problems that the students needed to pay attention to in their study, and guided the students to think and discuss according to the discussions and feedback. Towards the end of the class, the teacher guided the students to review and summarize the important knowledge points of the lesson. After each class, the students were requested to submit homework to the platform, raise questions in online forums or review teaching videos (Figure 2). All study data were recorded via the platform and could be accessed by the teacher.

Figure 2 Blended learning in the experimental group

\section{Control group}

\section{Teaching arrangement}

All learning resources were identical in the experimental group, except the absence of pre-recorded lecture videos for the control group.

\section{Traditional case-centered seminars}

The control group received offline case-centered learning via seminars throughout the two semesters. Each seminar involved approximately 20 students. In class, students formed small groups to discuss the cases under the guidance of the teacher. Subsequently, the teacher randomly selected groups to answer questions. Comments and explanations were provided by the teacher according to the answers. Additionally, the teacher guided the students to think, discuss, and summarize the knowledge points of the class. When class was almost over, quizzes were conducted to monitor the students' mastery of the lesson. After class, the students were required to summarize the key knowledge points and submit the summary.

\section{Evaluation of learning outcome}

\section{Academic performance}


Both the experimental and control groups underwent the same final exam, quizzes, and homework. The maximum total score for the course was 100 . The total score was determined using the following weights:

(1) Experimental group: final exam, $50 \%$; quiz, $20 \%$; online learning progress requirements, $15 \%$; discussion, $10 \%$; and homework, $5 \%$.

(2) Control group: final exam, 50\%; quiz, 20\%; course notes, 15\%; discussion, 10\%; and homework, 5\%.

\section{Assessment of the critical thinking ability of students}

Numerous tools, such as the California Critical Thinking Disposition Inventory (CCTDI) [27] and the California Critical Thinking Skill Test [28], have been designed to measure critical thinking in nursing. The CCTDI has been specifically developed and used for nursing students [29]. It has been shown to be a valid instrument for assessing critical thinking ability among nursing students in different cultural contexts [30]. The population included in the present study consisted of Chinese students. Hence, the California CTDI-Chinese Version (CTDI-CV), which was translated, modified, and validated by Chinese researchers, was more suitable than the original [31]. The CTDI-CV exhibits a good overall content validity index (0.89) and Cronbach's alpha (0.90), indicating satisfactory content validity and internal consistency, respectively [31].

The CCTDI measures overall critical thinking disposition. It consists of seven subscales that measure the following dispositions: truth-seeking, open-mindedness, analyticity, systematicity, critical thinking self-confidence, inquisitiveness, and cognitive maturity. Potential scores range from 5 to 60 for each subscale, with a maximum total score of 420 . The students in the two classes completed the questionnaire prior to and following the teaching experiment.

\section{Statistical analysis}

All statistical analyses were conducted using the IBM Statistical Package for the Social Sciences (SPSS), Version 22.0 (IBM Corp., Armonk, NY, USA). Mean and standard deviation were used to represent the normally distributed continuous data, while median (M) and quartiles $\left(\mathrm{P}_{25}, \mathrm{P}_{75}\right)$ were used to represent the non-normally distributed continuous data. If the continuous variables were normally distributed and exhibited homogeneity of variance, the t-test was used to assess the difference in learning outcomes between the two groups. Otherwise, the nonparametric rank-sum test was used. The chi-squared test was used to compare the baseline characteristics (regarding categorical variables) between the two groups. The significance level was set at 0.05 .

\section{Results}

\section{Participant characteristics}

Prior to starting the Medical Nursing course, 295 students completed the CTDI-CV questionnaire (164 and 131 in the experimental and control groups, respectively). However, in the second semester, 24 students changed their major to Midwifery, three students changed their major to Public Health, and one student discontinued the course. Consequently, at the end of the Medical Nursing course, 269 students met the inclusion criteria (151 and 118 students, respectively) (Figure 3).

Figure 3 Study flow diagram

\section{Academic performance of participants}

Prior to the initiation of the Medical Nursing course, the students in the control group were significantly superior to those in the experimental group in terms of academic performance regarding the seven Professional Basic courses $(p<0.05)$. After the 1year Medical Nursing course, there was no significant difference in the academic performance between the two classes (median scores of 81 and 80 in the experimental and control groups, respectively; $p=0.112$ ).

\section{Critical thinking ability of participants}


There were no significant differences in the total CTDI-CV or dimension scores between the two classes, prior to or after participating in the teaching program. In the experimental group, the score for the critical thinking self-confidence dimension was significantly higher after the teaching experiment. In the control group, there were significant improvements in the total CTDI-CV score and two of the seven dimensions: truth-seeking and systematicity (Table 3).

\section{Discussion}

\section{Effect on academic performance}

In this study, we compared the academic performance between the experimental and control groups in terms of the Professional Basic courses of the previous year, and found significant differences in all seven topics. This indicated that the students in the control group exhibited generally superior academic performance compared with those in the experimental group. However, after the 1-year Medical Nursing course, there was no significant difference in academic performance between the two classes. However, it is noteworthy that the median score of the experimental group (81) was slightly higher than that reported in the control group (80), suggesting that blended learning may improve academic performance.

The majority of previous studies have compared blended learning with traditional didactic teaching, and the effect of blended learning on academic performance remains controversial. Some researchers found a significant increase in the academic performance of students taught using blended learning [32]. In contrast, other researchers did not report a significant increase in academic performance [33]. This may be partly explained by the inconsistency in the use of instruments to assess student performance. In our study, a more comprehensive assessment was adopted to evaluate student learning outcomes. Nevertheless, there were no significant differences found in academic performance between the two types of teaching methods.

\section{Effect on critical thinking ability}

As shown in Table 4, there were no significant differences in the overall critical thinking ability (based on the total CTDI-CV score) or the scores of the seven dimensions between the two classes, either prior to or after the course. Therefore, there was no difference in the improvement of critical thinking ability between the blended and offline case-centered learning groups. However, after blended learning, the experimental group scored significantly higher for the critical thinking self-confidence dimension compared with baseline. The control group achieved significant improvements in the total CTDI-CV score and the dimensions of truth-seeking and systematicity. This indicates that blended learning improved the self-confidence of students regarding critical thinking. Notably, offline case-centered learning improved the ability of students regarding truth-seeking and systematicity, and their overall critical thinking ability (based on the total CTDI-CV score). These results are consistent with those of other studies conducted among nursing students, which showed improvements in critical thinking skills based on effective teaching methods [29, 34-36].

Blended learning focused on the subject status of the students, and provided opportunities to express themselves in class. Students who expressed their ideas in the process of learning and discussion gained recognition from teachers and classmates, thereby enhancing their confidence and increasing their willingness to express themselves in subsequent classes.

Offline case-centered learning employed the use of case studies. The students were divided into small groups to explore and solve problems regarding the cases. During this process, the teacher provided guidance and assistance to improve the logical reasoning and problem-solving ability of students. Subsequently, the teacher summarized the key points from the seminar. After the seminar, the students were requested to summarize their knowledge in a timely manner, which can improve critical thinking ability.

In this study, offline case-centered learning led to improvements in two CTDI-CV dimensions, while blended learning only improved one. This may be attributable to the different teaching methods and teaching schedules between the two classes. Offline case-centered learning focused on holistic learning with 74 lecture hours, while blended learning emphasized 
fragmented learning with 26 lecture hours. Additionally, the blended learning discussions were conducted prior to each class by the students themselves, while the offline case-centered learning discussions were performed under the instruction of the teacher. Thus, the systematicity of students was improved by the offline case-centered learning. A previous study supported the use of scientific discussions as beneficial educational tools to develop critical thinking [37]. However, further studies should assess the discussion strategies used in blended learning.

There were certain limitations in this study. Firstly, the study was conducted for only two semesters in one subject, which may limit the validity and reliability of the findings regarding the promotion of critical thinking. Thus, studies assessing the effectiveness of blended learning in other nursing subjects are necessary. Secondly, we did not interview students regarding their feelings and experiences. Therefore, qualitative research is also warranted. Moreover, it would be useful to follow up the students in this study, and evaluate their performance in clinical practice.

In summary, the findings of our study imply that blended and offline case-centered learning have great potential for promoting critical thinking. Optimization of the teaching design in future studies is vital to explore the effects of blended learning among undergraduate nursing students.

\section{Conclusions}

This study investigated the effects of blended versus offline learning (both based on case-centered learning) on academic performance and the development of critical thinking among undergraduate nursing students. The results confirm that components of critical thinking are improved by both blended and offline case-centered learning. In the future, blended and offline case-centered learning could be implemented in other nursing subjects.

\section{Abbreviations}

CTDI-CV: Critical Thinking Disposition Inventory-Chinese Version; CBL: case-based learning

\section{Declarations}

\section{Ethics approval and consent to participate}

Ethical approval was granted by the Education Department of Fujian Medical University (reference number: +86-059122862100). Students were informed regarding the study and signed consent forms.

\section{Consent for publication}

Not applicable

\section{Availability of data and materials}

The dataset used during the study is available from the corresponding author on reasonable request.

\section{Competing interests}

The authors declare that they have no competing interests.

\section{Funding}

This study was supported by the program of Research of Medical Education in 2018, Medical Education Branch of the Chinese Medical Association and Medical Education Committee of the Chinese Society of Higher Education (2018A-N18033), Beijing, China. The two sponsors had no role in the design of the study or collection, analysis, and interpretation of data; writing of the report; or the decision to submit the article for publication. 


\section{Authors' contributions}

$\mathrm{RH}$ organized the data collection and wrote the application for ethical approval. All authors made substantial contributions to the design of teaching. All authors contributed to data analysis and the drafting and reviewing of the manuscript. All authors approved the final manuscript for submission and have agreed to be accountable for the accuracy and integrity of the work.

\section{Acknowledgements}

We thank Mei-Ci Peng, who provided the Chinese version of the California Critical Thinking Disposition Inventory questionnaire for this study. Additionally, we thank all the participants.

\section{References}

1. Simpson E, Courtney M. Critical thinking in nursing education: literature review. Int J Nurs Pract. 2002;8:89-98.

2. Kong LN, Qin B, Zhou YQ, Mou SY, Gao HM. The effectiveness of problem-based learning on development of nursing students' critical thinking: a systematic review and meta-analysis. Int J Nurs Stud. 2014;51(3):458-469.

3. Chang MJ, Chang YJ, Kuo SH, Yang YH, Chou FH. Relationships between critical thinking ability and nursing competence in clinical nurses. J Clin Nurs. 2011;20(21-22):3224-32.

4. Papathanasiou IV, Kleisiaris CF, Fradelos EC, Kakou K, Kourkouta L. Critical thinking: the development of an essential skill for nursing students. Acta Inform Med. 2014;22(4):283-6.

5. Sommers CL. Measurement of critical thinking, clinical reasoning, and clinical judgment in culturally diverse nursing students - a literature review. Nurse Educ Pract. 2018;30:91-100.

6. Carley A. Using technology to enhance nurse practitioner student engagement. Nurse Pract. 2015;40(7):47-54.

7. Kaddoura MA. Critical thinking skills of nursing students in lecture-based teaching and case-based learning. Int $J$ Scholarship of Teaching and Learning. 2011;5(2):1-18.

8. Thistlethwaite JE, Davies D, Ekeocha S, Kidd JM, MacDougall C, Matthews P, et al. The effectiveness of case-based learning in health professional education. A BEME systematic review: BEME Guide No. 23. Med Teach. 2012;34(6):e42144.

9. McLean SF. Case-based learning and its application in medical and health-care fields: a review of worldwide literature. J Med Educ Curric Dev. 2016;27:3.

10. Kantar LD, Massouh A. Case-based learning: What traditional curricula fail to teach. Nurse Educ Today. 2015;35(8):e8-14.

11. Gholami M, Saki M, Toulabi T, Kordestani Moghadam P, Hossein Pour AH, Dostizadeh R. Iranian nursing students' experiences of case-based learning: a qualitative study. J Prof Nurs. 2017;33(3):241-9.

12. Hofsten A, Gustafsson C, Haggstrom E. Case seminars open doors to deeper understanding - Nursing students' experiences of learning. Nurse Educ Today. 2010;30(6):533-8.

13. Majeed F. Effectiveness of case-based teaching of physiology for nursing students. Journal of Taibah University Medical Sciences. 2014;9(4):289-92.

14. Yoo MS, Park HR. Effects of case-based learning on communication skills, problem-solving ability, and learning motivation in nursing students. Nurs Health Sci. 2015;17(2):166-72.

15. Yoo MS, Park JH. Effect of case-based learning on the development of graduate nurses' problem-solving ability. Nurse Educ Today. 2014;34(1):47-51.

16. Park JY, Woo CH, Yoo JY. Effects of blended cardiopulmonary resuscitation and defibrillation E-learning on nursing students' self-efficacy, problem solving, and psychomotor pkills. Comput Inform Nurs. 2016;34(6):272-80.

17. Garrison DR, Kanuka H. Blended learning: Uncovering its transformative potential in higher education. The Internet and Higher Education. 2004; 7(2):95-105. 
18. Walker S, Dwyer T, Moxham L, Broadbent M, Sander T. Facilitator versus preceptor: which offers the best support to undergraduate nursing students? Nurse Educ Today. 2013;33(5):530-5.

19. Pereira JA, Pleguezuelos E, Meri A, Molina-Ros A, Molina-Tomas MC, Masdeu C. Effectiveness of using blended learning strategies for teaching and learning human anatomy. Med Educ. 2007;41(2):189-95.

20. Ireland J, Johnson N, Adams D, Eboh W, Mowatt E. Blended learning in education: effects on knowledge and attitude. Br J Nurs. 2009;18(2):124-30.

21. Hsu L, Hsieh S. Effects of a blended learning module on self-reported learning performances in baccalaureate nursing students. J Adv Nurs. 2011;67(11):2435-44.

22. Gagnon MP, Gagnon J, Desmartis M, Njoya M. The impact of blended teaching on knowledge, satisfaction, and selfdirected learning in nursing undergraduates: a randomized, controlled trial. Nurs Educ Perspect. 2013;34(6):377-82.

23. Shorey S, Kowitlawakul Y, Devi MK, Chen HC, Soong SKA, Ang E. Blended learning pedagogy designed for communication module among undergraduate nursing students: a quasi-experimental study. Nurse Educ Today. 2018;61:120-6.

24. Coyne E, Rands H, Frommolt V, Kain V, Plugge M, Mitchell M. Investigation of blended learning video resources to teach health students clinical skills: an integrative review. Nurse Educ Today. 2018;63:101-7.

25. McCutcheon K, O'Halloran P, Lohan M. Online learning versus blended learning of clinical supervisee skills with preregistration nursing students: a randomised controlled trial. Int J Nurs Stud. 2018;82:30-9.

26. Zolfaghari M, Negarandeh R, Eybpoosh S. Developing a blended learning program for nursing and midwifery students in Iran: Process and preliminary outcomes. Iran J Nurs Midwifery Res. 2013;18(1):20-6.

27. Facione NC, Facione PA, Sanchez CA. Critical thinking disposition as a measure of competent clinical judgment: the development of the California Critical Thinking Disposition Inventory. J Nurs Educ. 1994;33(8):345-50.

28. Facione NC, Peter PA: The California Critical Thinking Skill Test (CCTST) Form A \& Form B. In: Test Manual. Millbrae, CA: California Academic Press; 1994.

29. Fero LJ, O'Donnell JM, Zullo TG, Dabbs AD, Kitutu J, Samosky JT, et al. Critical thinking skills in nursing students: comparison of simulation-based performance with metrics. J Adv Nurs. 2010;66(10):2182-93.

30. Yeh ML. Assessing the reliability and validity of the Chinese version of the California Critical Thinking Disposition Inventory. Int J Nurs Stud. 2002;39(2):123-32.

31. Peng M, Wang G, Chen J, Chen M, Bai H, Li S, et.al. Validity and reliability of the Chinese critical thinking disposition inventory (Article in Chinese). Chinese J Nurs. 2004;39(9):644-7.

32. Kiviniemi MT. Effects of a blended learning approach on student outcomes in a graduate-level public health course. BMC Med Educ. 2014;14:47.

33. Sajid MR, Laheji AF, Abothenain F, Salam Y, AlJayar D, Obeidat A. Can blended learning and the flipped classroom improve student learning and satisfaction in Saudi Arabia? Int J Med Educ. 2016;7:281-5.

34. Carter AG, Creedy DK, Sidebotham M. Efficacy of teaching methods used to develop critical thinking in nursing and midwifery undergraduate students: a systematic review of the literature. Nurse Educ Today. 2016;40:209-18.

35. Gyeong JA, Myung SY. Critical thinking and learning styles of nursing students at the Baccalaureate nursing program in Korea. Contemp Nurse. 2008;29(1):100-9.

36. Hong S, Yu P. Comparison of the effectiveness of two styles of case-based learning implemented in lectures for developing nursing students' critical thinking ability: a randomized controlled trial. Int J Nurs Stud. 2017;68:16-24.

37. Borglin G, Fagerstrom C. Nursing students' understanding of critical thinking and appraisal and academic writing: a descriptive, qualitative study. Nurse Educ Pract. 2012;12(6):356-60.

\section{Tables}

Table 1 Participant general information 


\begin{tabular}{|c|c|c|c|c|}
\hline Variable & Experimental group $(\mathrm{n}=164)$ & Control group $(n=131)$ & $\chi^{2}$ value & $\mathrm{p}$ value \\
\hline \multicolumn{5}{|l|}{ Gender } \\
\hline Female & 141 & 119 & 1.648 & 0.199 \\
\hline Male & 23 & 12 & & \\
\hline \multicolumn{5}{|c|}{ Choose nursing as first major } \\
\hline Yes & 100 & 84 & 0.307 & 0.579 \\
\hline No & 64 & 47 & & \\
\hline \multicolumn{5}{|c|}{ Like or dislike nursing } \\
\hline Like & 111 & 89 & 0.002 & 0.963 \\
\hline Dislike & 53 & 42 & & \\
\hline \multicolumn{5}{|c|}{ Is a class leader } \\
\hline Yes & 77 & 53 & 1.246 & 0.264 \\
\hline No & 87 & 78 & & \\
\hline \multicolumn{5}{|c|}{ Reading except textbooks } \\
\hline Yes & 120 & 103 & 1.175 & 0.278 \\
\hline No & 44 & 28 & & \\
\hline \multicolumn{5}{|c|}{ Experienced critical thinking course } \\
\hline $\begin{array}{l}\text { Yes } \\
\text { No }\end{array}$ & $\begin{array}{l}136 \\
28\end{array}$ & $\begin{array}{l}102 \\
29\end{array}$ & 1.198 & 0.274 \\
\hline
\end{tabular}

Table 3 Comparison of the total CTDI-CV scores and each dimension score between the two classes

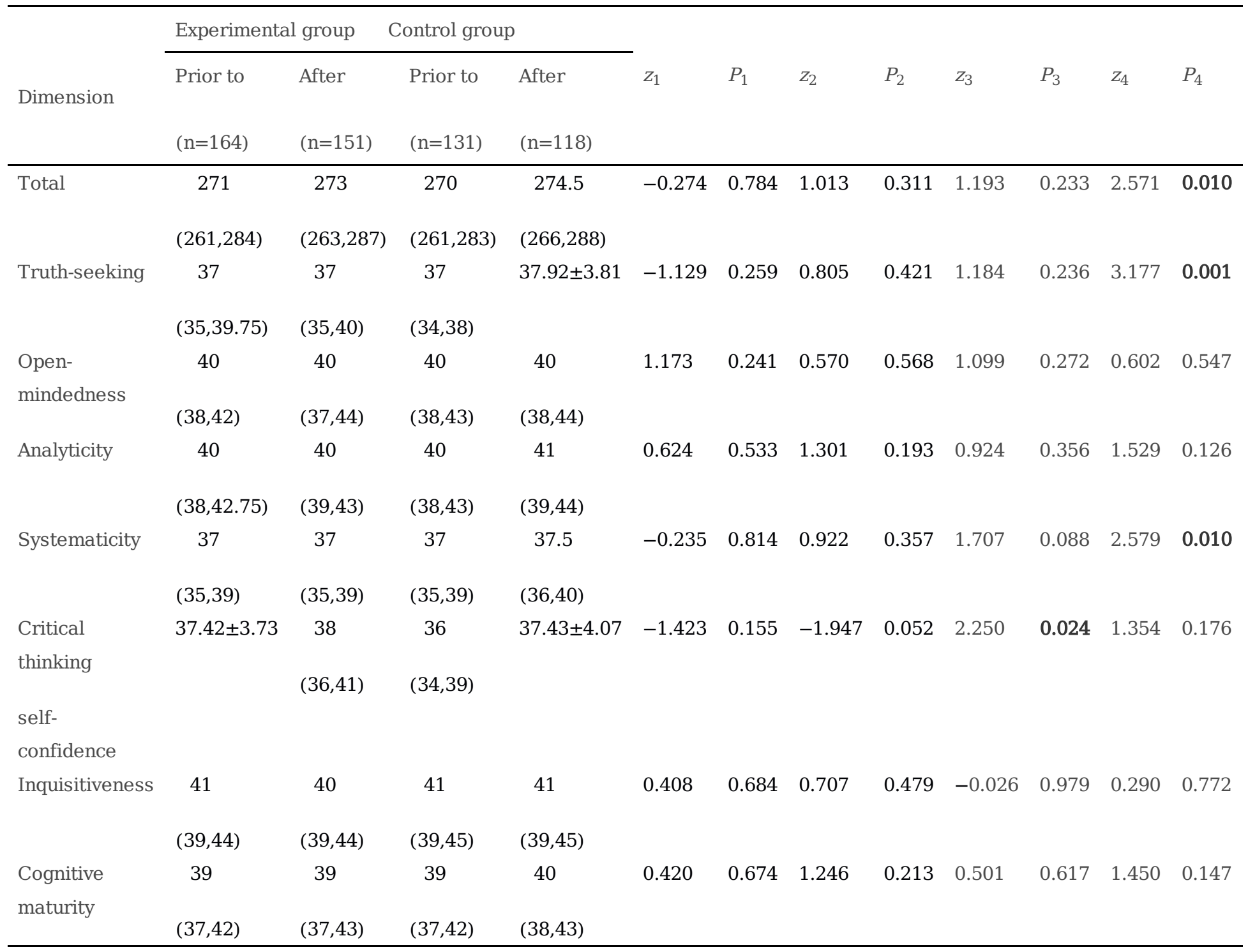

$z_{1}$ and $P_{1}$ correspond to the comparison of the two groups prior to the teaching experiment; $z_{2}$ and $P_{2}$ correspond to the comparison of the two groups after the teaching experiment; $z 3$ and $P_{3}$ correspond to the comparison of the experimental group prior to and after the 
teaching experiment; $z_{4}$ and $P_{4}$ correspond to the comparison of the control group prior to and after the teaching experiment.

CTDI-CV: Critical Thinking Disposition Inventory-Chinese Version

Table 2 Comparison of academic performance in the Professional Basic courses in the previous academic year

\begin{tabular}{|c|c|c|c|c|c|c|c|c|c|c|}
\hline \multirow[t]{2}{*}{ Professional basic course } & \multicolumn{4}{|c|}{ Experimental group $(\mathrm{n}=151)$} & \multicolumn{4}{|c|}{ Control group ( $\mathrm{n}=118)$} & \multirow{2}{*}{$\begin{array}{l}\mathrm{z} / \mathrm{t} \\
\text { value }\end{array}$} & \multirow{2}{*}{$\begin{array}{l}\mathrm{p} \\
\text { value }\end{array}$} \\
\hline & Median & $\left(\mathrm{P}_{25}, \mathrm{P}_{75}\right)$ & Mean & $\mathrm{SD}$ & Median & $\left(\mathrm{P}_{25}, \mathrm{P}_{75}\right)$ & Mean & SD & & \\
\hline Anatomy & 60 & $(66,72)$ & l & l & l & l & 70.38 & 9.84 & 3.878 & 0.000 \\
\hline Physiology & 67 & $(61,72)$ & l & l & l & l & 71.36 & 8.30 & 3.944 & 0.000 \\
\hline Introduction to Nursing Sciences & 64 & $(61,68)$ & l & l & 65 & $(62,70)$ & l & I & 2.342 & 0.019 \\
\hline Pathology and Pathophysiology & l & l & 69.77 & 8.24 & l & 1 & 75.07 & 9.07 & -5.008 & 0.000 \\
\hline Pathogenic Biology and Immunology & 70 & $(65,76)$ & l & l & 73 & $(68,78.25)$ & l & l & 2.694 & 0.007 \\
\hline Pharmacology & 71 & $(64,77)$ & 1 & 1 & l & l & 73.79 & 10.14 & 3.248 & 0.001 \\
\hline Health Assessment & 74 & $(70,78)$ & l & l & 78 & $(74,83)$ & l & l & 4.607 & 0.000 \\
\hline
\end{tabular}

\section{Figures}

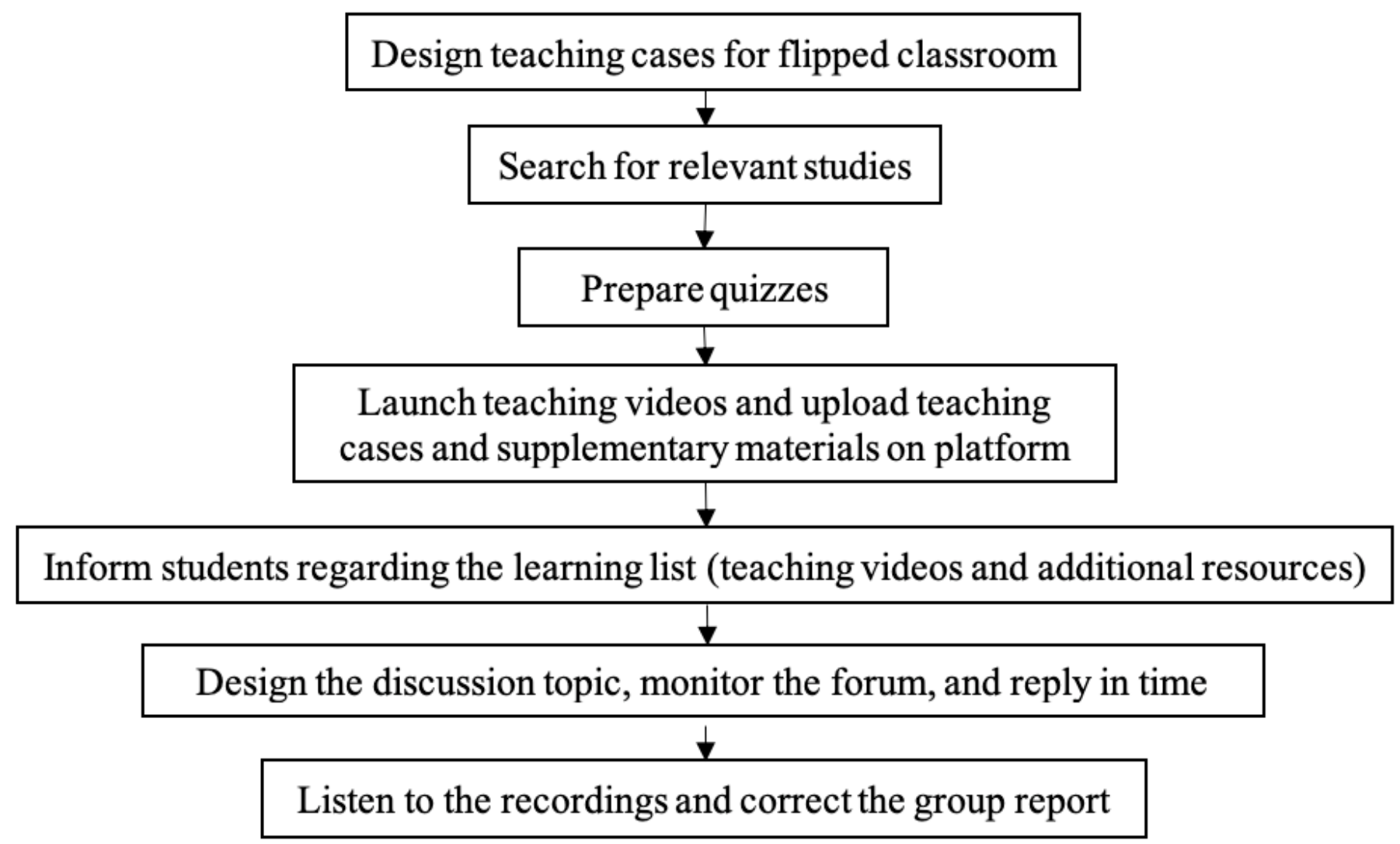

Figure 1 


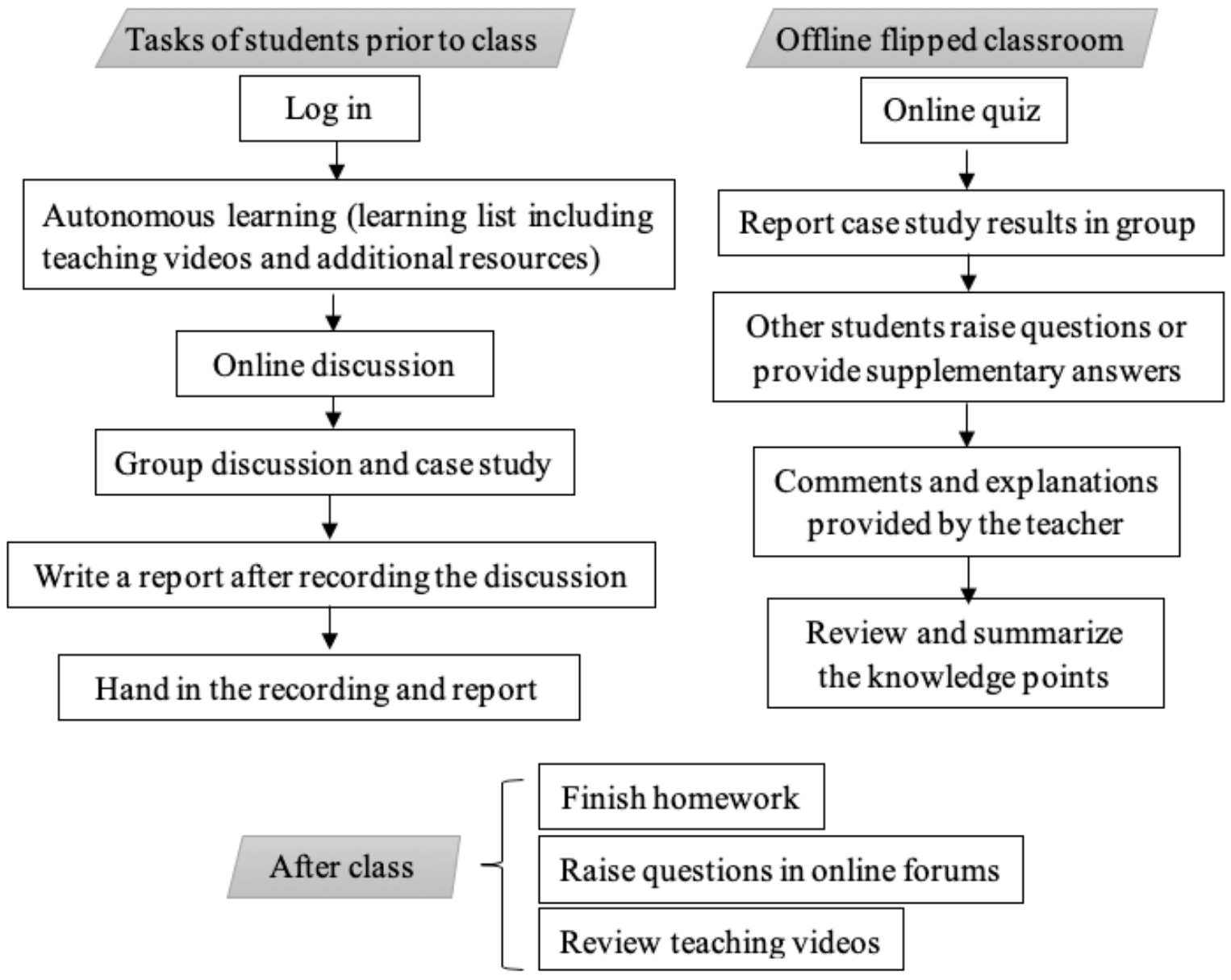

Figure 2

Blended learning in the experimental group 


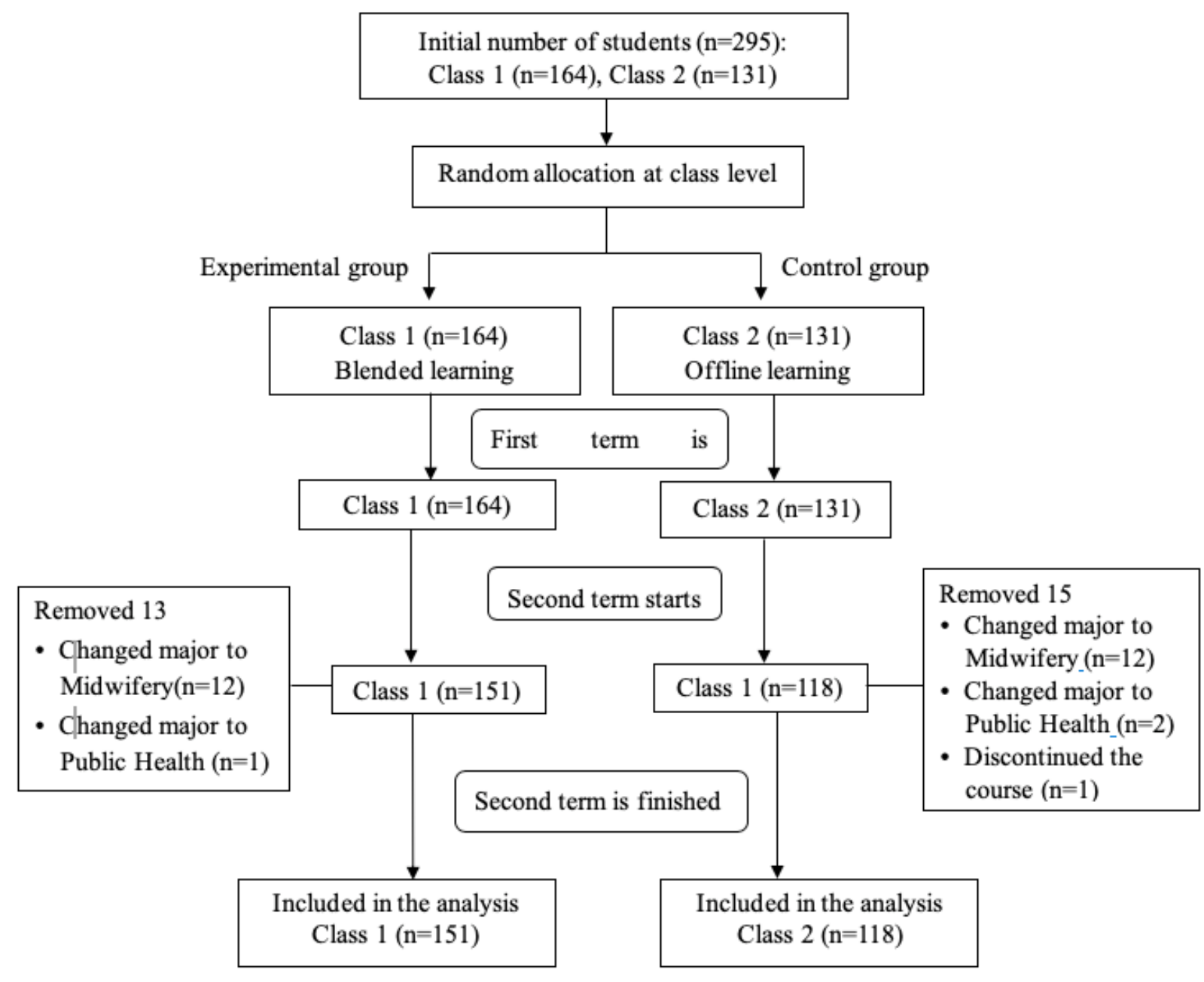

Figure 3

Study flow diagram

\section{Supplementary Files}

This is a list of supplementary files associated with this preprint. Click to download.

- AdditionalFile.docx 